\title{
Gravity analysis offshore the Canary Islands from a systematic survey
}

\author{
A. Carbó ${ }^{1}$, A. Muñoz-Martín ${ }^{1, *}$, P. Llanes ${ }^{1}$, J. Álvarez ${ }^{1} \&$ EEZ Working Group** \\ ${ }^{1}$ Universidad Complutense de Madrid. Facultad de Ciencias Geológicas. Departamento de Geodinámica. \\ 28040 Madrid (Spain) *Corresponding Author (Phone: +34-913944834; Fax: +34-913944631; E-mail: \\ amunoz@geo.ucm.es)
}

Key words: Bouguer anomaly, Canary Islands, free air anomaly, geodynamics, gradient zone, marine gravity

\begin{abstract}
As part of a systematic mapping program of the Hydrographic and Oceanographic Research Plan for the Spanish Exclusive Economic Zone (EEZ), gravity surveys were carried out offshore the Canary Islands. Using the gravity data collected during cruises between 1998 and 2000 aboard the RV Hesperides and satellite and land data, we construct free air and Bouguer anomaly maps and discuss the geodynamic implications.

Using maps of Bouguer anomaly, free air anomaly, vertical derivative, long wavelength Bouguer anomaly and short wavelength anomaly, a detailed description of the gravity characteristics of the archipelago is presented, describing gravity anomalies from a geologic point of view. The character of the crust throughout the studied area has been defined, as well as high gradient zones that limit crustal blocks of different density. High gradient zones have been mapped for the first time and interpreted as fracture zones, taking into account geophysical and geological information. Gravity highs and lows have been studied and related to crustal, mantle and volcanic effects.
\end{abstract}

\section{Introduction}

In 1995, the 'Instituto Español de Oceanografía' and the 'Instituto Hidrográfico de la Marina' undertook a geologic and oceanographic research study of the Spanish Exclusive Economic Zone (EEZ). The main objectives of this research were to map the EEZ in order to obtain bathymetric charts and to perform a geophysical survey, consisting of gravity, magnetic and other information compatible with a 10 knot ship velocity. The EEZ program involved the cooperation of the 'Real Observatorio de la Armada', which was responsible for magnetic data, and the 'Departamento de Geodinámica, Universidad Complutense de Madrid', responsible for gravity data. The investigations of the EEZ program were carried out offshore the Canary Archipelago (Figures 1 and 2), during cruises EEZ-1998, EEZ-1999 and EEZ-2000.

These cruises constituted the first systematic gravity survey performed in the Canary Islands region, providing data acquired using the same self-consistent acquisition system along quasi-regularly spaced sur- vey tracks. The purpose of this paper is to present consistent, regional gravity maps of the Canary Islands region, and to interpret some of the geodynamic implications they provide. The publication of these maps is of great interest for tectonic and geodynamics studies. Among other applications, these maps, combined with other geological and geophysical information, provide constraints on the different tectonic models proposed to explain the origin of the Canary Islands (e.g., Anguita and Hernán, 2000; Carracedo et al., 1998), on the structure of the island crust and upper mantle (e.g. Watts et al., 1997), on the thermal and mechanical properties of the oceanic lithosphere underneath the archipelago (e.g. Canales and Dañobeitia, 1998), and on the nature of the ocean-continent transition in the region (Watts and Marr, 1995).

\section{Geological setting and previous geophysical work}

The Canary Islands are an intraplate volcanic archipelago formed of seven volcanic islands located 


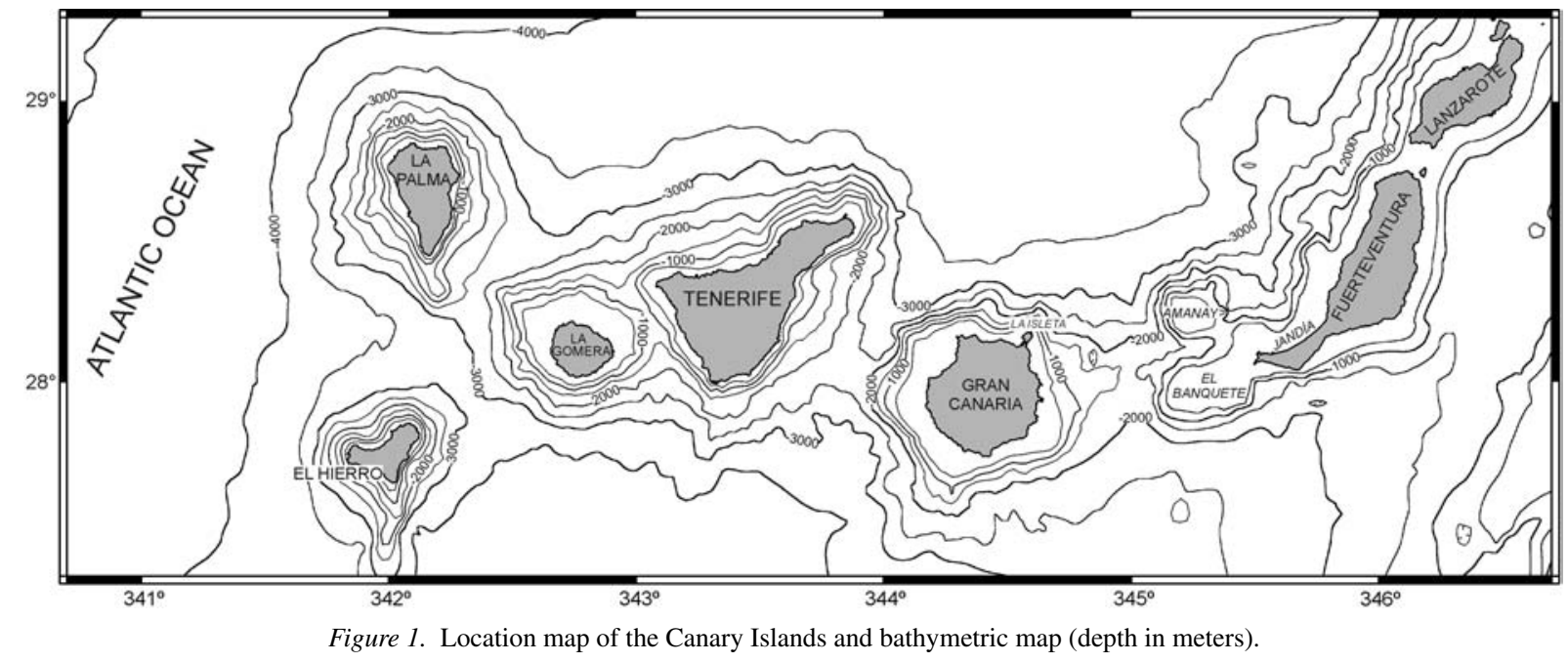

in the eastern Atlantic Ocean, close to the northwest African continental margin (Figure 1) and lying on Jurassic oceanic crust, between isochrons M21 and S1 (150 and $175 \mathrm{Ma}$, Roest et al., 1992). The easternmost island, Fuerteventura, is only $100 \mathrm{~km}$ from the African coast. Their proximity to the continent, together with the sparse data available, influenced discussions about the character of the crust under the Canaries. Hausen (1962) suggested a continental character for the islands while Rothe and Schmincke (1968) proposed a continental character for the eastern islands (Lanzarote and Fuerteventura) and an oceanic one for the western islands. Fuster et al. (1968) advocated an oceanic origin for all the Canary Islands. The oceanic character of the lithosphere under the Canaries has been confirmed by seismic multichannel reflection and refraction studies at both a crustal and a lithospheric scale (Bosshard and MacFarlane, 1970; Banda et al., 1981; Watts et al., 1997).

The first marine gravity study of the Canary Archipelago, together with some refraction seismic profiles, was published by Dash and Bosshard (1969) for the western islands. They obtained free air and Bouguer anomaly maps using a $50 \mathrm{mGal}$ contour interval, described how free air anomalies followed the bathymetry quite closely, and noticed the absence of an offshore belt of negative anomalies associated with the islands, such as seen in Hawaii (Watts and Talwani, 1975). Based on Bouguer anomalies they interpreted all the islands as independent structural blocks, except Tenerife and La Gomera, which lie in the same block. They also interpreted two main faults, one between Gran Canaria and Tenerife trending NE-SW, and another through Tenerife, La Gomera and El Hierro trending in the same direction. Dash and Bosshard (1969) proposed oceanic crust for the west and a transitional type in the central area of the archipelago. Using the same data for the western island, Bosshard and MacFarlane (1970) constructed a more detailed Bouguer anomaly map and used the free air values to compute the depth of the Mohorovicic discontinuity and Bouguer values for structural models, but their general conclusions were the same as those of Dash and Bosshard (1969).

Regional and local gravity anomaly data were presented by MacFarlane and Ridley for the islands of Tenerife (1968) and Lanzarote (1969). Their results point to a gradational position of the islands between a truly oceanic and a truly continental environment. Bouguer anomaly values increase from a fairly typical continental value of $25 \mathrm{mGal}$ over the continental shelf to over $250 \mathrm{mGal}$ west of El Hierro. An interpretation of the regional and local gravity data was attempted and some broader genetic implications were briefly discussed. More recent local gravity studies have been done, basically to define the structure and volcanism in Tenerife and Lanzarote (Ablay and Kearey, 2000; Araña et al., 2000; Camacho et al., 2001; Vieira et al., 1986). On a regional scale the most recent studies focus on lithosphere analysis of the Canary Islands using both seismic and gravity data (Canales and Dañobeitia, 1998; Dañobeitia et al., 1994; Ranero et al., 1995; Watts, 1986). 


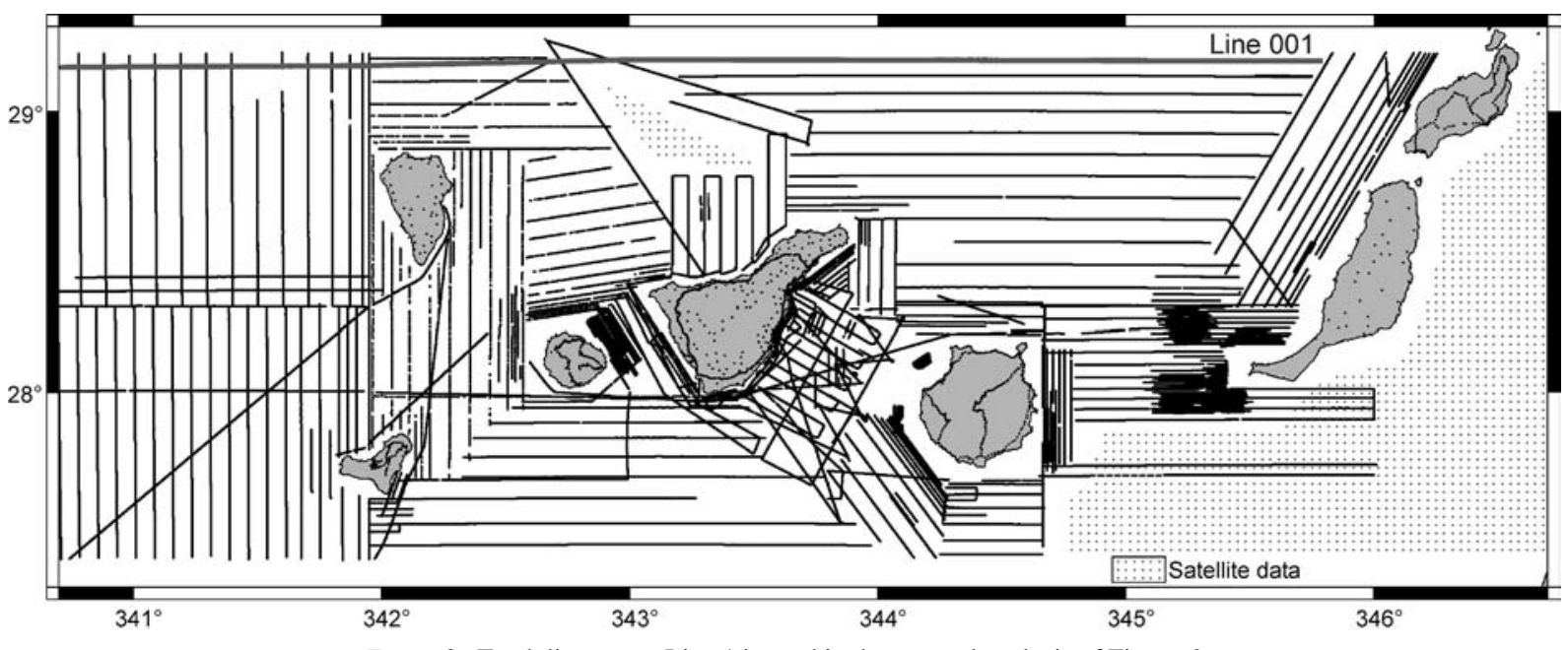

Figure 2. Track lines map. Line 1 is used in the spectral analysis of Figure 6.

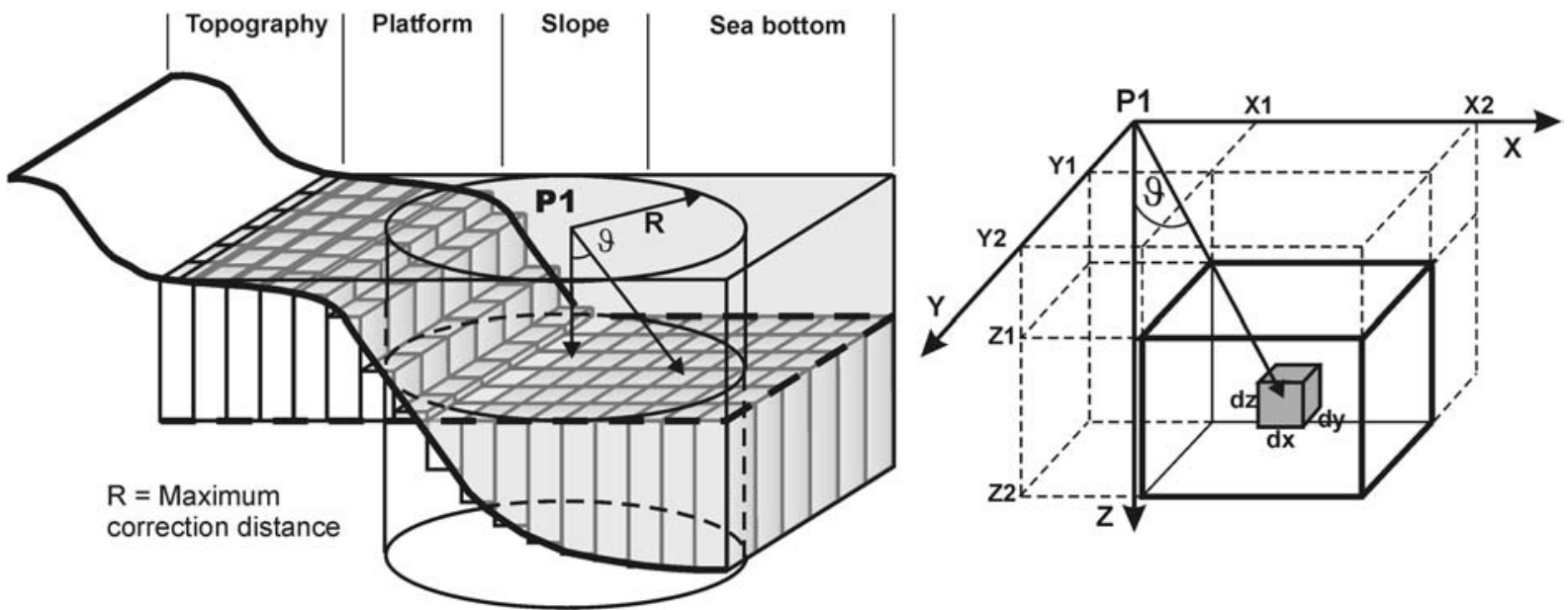

Figure 3. Block diagram that shows the parameters used in 'sea bottom corrections' (left) and variables used in calculations (right).

\section{Data Collection}

An area of more than $124000 \mathrm{~km}^{2}$ offshore the Canaries is studied here. The marine gravity data were collected during the EEZ cruises, where a total of 338,421 useful readings were obtained (Figure 2). Satellite-altimetry-derived gravity data (Sandwell and Smith, 1997) as well as data from a cruise previous to the EEZ project (Teide-95) were used to complete the study area. Land gravity data from the 'Instituto Geográfico Nacional' database, distributed over the seven major islands (I.G.N., 1996), were also used to avoid border errors inside the studied area. The locations of track lines together with land and satellite data are shown in Figure 2.
The acquisition of marine gravity data was carried out aboard the RV Hespérides using a $\pm 1 \mathrm{mGal}$ accuracy Bell Aerospace BGM-3 gravity system, with an automatic pitch and roll elimination. The gravity meter used for the land link was a $\pm 0.01 \mathrm{mGal}$ accuracy LaCoste \& Romberg. The offshore gravity data set was corrected for instrumental drift and tied into the land network throughout the 'Instituto Geográfico Nacional' gravity bases of Cartagena (SE of Iberian Peninsula) and Las Palmas (Gran Canaria).

Ship navigation data was obtained by two simultaneous differential GPS (DGPS) systems integrated with RV Hespérides' central navigation system. A local DGPS base station and a second system based on a regional base station network were used, resulting 
in better than $5 \mathrm{~m}$ navigation accuracy. Water depth was recorded with both a multi-beam echosounder Simrad EM-12S and single beam echosounder Simrad EA-500.

\section{Data Processing}

Ship gravity data was merged with navigation data (date, time, ship's speed, water depth, course, latitude and longitude), and the Eötvos effect was corrected. Gravity data were reduced to the 1967 Geodetic Reference System (GRS), the water slab was corrected using a density of $1.03 \mathrm{~g} / \mathrm{cm}^{3}$ and Free-Air and Bouguer anomalies were calculated following the procedure of Nettleton (1976). Land gravity data were also reduced to the 1967 GRS using a density of $2.67 \mathrm{~g} / \mathrm{cm}^{3}$ for the Bouguer correction.

A total of 397 processed track lines, containing the data described above, were included in a georeferenced database. Spikes were corrected in each line and, due to the regional character of the map, high frequency anomalies were eliminated by a low pass filter (anomalies under $1.5 \mathrm{~km}$ of wavelength).

\section{Sea bottom correction}

Nettleton (1976, Chapter 5) described how to correct the effect produced by the water slab and irregularities of the ocean floor. This author calls the result of applying these corrections 'Bouguer anomalies', though the corrections at sea are not exactly equal to those applied on land. It should be remembered that the correction for the water slab is done with a slab of water situated below the reference level. Also, the gravity effect produced by sea bottom irregularities, treated as positive and negative spikes above the lower limit of the slab of water, are computed at sea level and can be positive or negative. When working in areas close to the continental slope, or in archipelagos with large bathymetric variations, these corrections should be applied so that the map of gravity anomalies, obtained at sea level, reflects the distribution of the densities at the sea bottom and is not heavily affected by bathymetric irregularities.

The correction of these effects was performed for each point at which a reading was taken, using an original computer programme (LANZADAF). The programme can be explained as follows (Figure 3). The programme uses two matrixes: appearing in the first data matrix (DM) are the geographic coordinates of the reading points to be corrected, their bathymetry and the free air anomaly; in the second prism matrix (PM) are the geographic coordinates of each regular prism into which the study area has been divided and their average depths. It is first necessary to divide the sea bottom into regular prisms with the sides defined and the altitudes equal to the average bathymetry at the base of each prism.

The flux of the programme is carried out following three levels described as follows and by repeating the process for each reading point.

(1) Bouguer slab correction. This is done in the classic way, though the density under consideration is the negative contrast arising from the presence of seawater and the thickness of the slab is the depth of the reading point.

(2) Creation of a residual prism matrix (RPM) with the same geometrical disposition as in the PM. The new geographic coordinates and their altitude will be established by the difference between those of the PM and those of the point to be corrected. It is evident that the altitudes defined in this way will be positive when the bottom surface in the position of the prisms is greater than the lower limit of the slab of water used for the Bouguer correction and negative in the opposite case (Figure 3 ).

(3) The sum of all the effects generated by the prisms of the RPM above the reading point and the elaboration of a departure matrix in the appropriate format to execute the mapping of Bouguer anomalies. The operation will be broadened to a distance at which the calculated effects will be irrelevant. The relative $\mathrm{X}$ and $\mathrm{Y}$ coordinates, the slab correction, the depth correction, the free air anomaly and the Bouguer anomaly are included in the departure matrix. The gravity effect of a regular prism, with a density $\delta$ over a point (Figure 3 ), is expressed by:

$$
g_{z}=\gamma \sigma \int_{x 1}^{x 2} d x \int_{y 1}^{y 2} d y \int_{z 1}^{z 2} \frac{z d z}{\left(x^{2}+y^{2}+z\right)^{\frac{3}{2}}}
$$

where $\gamma$ is the constant of universal gravitation and $\sigma$ the density of the prisms.

As a base of calculation for programming, we have used the solution of this integral proposed by Nagy (1966), because of its simplicity and appropriateness for the programming of the problem, although there have been a great many further advances (e.g., Plouff, 1976; Danés, 1982, Ma and Watts, 1994). In 


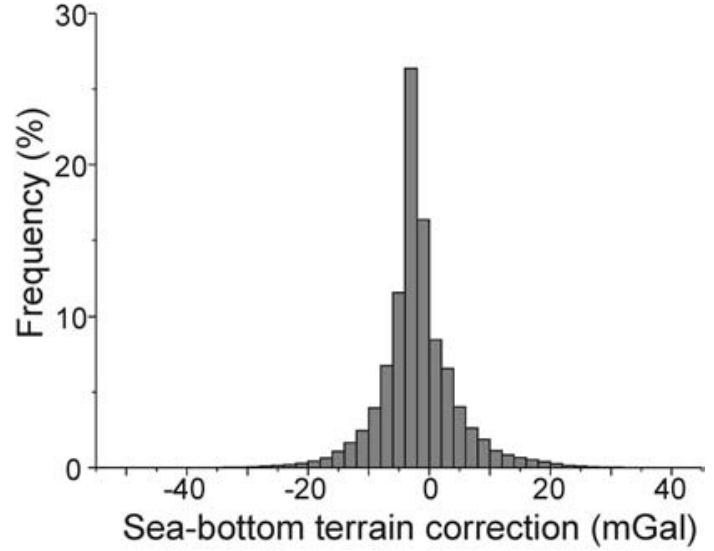

Figure 4. Histogram of sea bottom terrain values obtained for all the data.

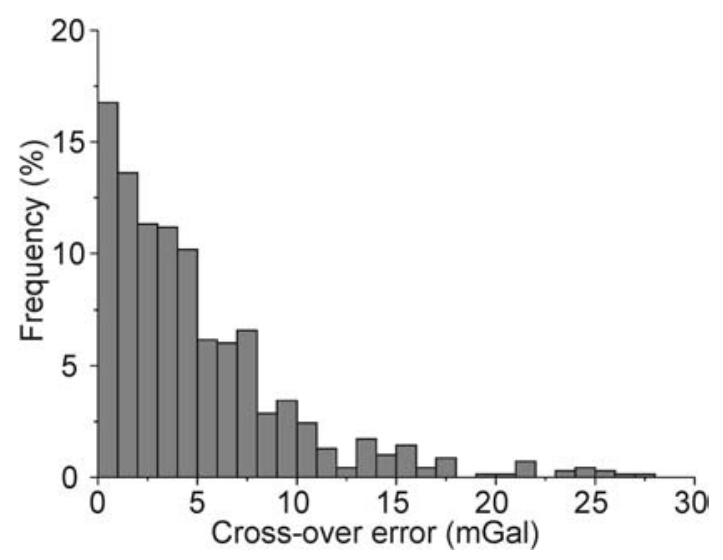

Figure 5. Histogram of differences between calculated Bouguer gravity anomalies at cross-over ship's tracks.

a complimentary way, Nagy (1966) also executes a classic topographical correction for nearby land elevations, breaking down the topography into straight prisms. This correction is necessary in cases like the Canary Islands, where altitudes of nearby emerged land reach 3500 meters above sea level.

The prism used was $2 \mathrm{~km}$ wide and the seabottom correction was extended to $22 \mathrm{~km}$. The digital elevation model used included satellite sea-bottom data (Smith and Sandwell, 1997) and land data (ETOPO30). Statistical analysis of the sea-bottom corrected values showed a mean value of $-1.92 \mathrm{mGal}$ and a standard deviation of $6.64 \mathrm{mGal}$ (Figure 4).

\section{Levelling correction}

To estimate the overall accuracy of the gravity measurements obtained during four different cruises, differences between gravity anomalies observed at intersecting ships' tracks were examined, since this is considered the best method to evaluate uncertainties in marine gravity data (Talwani, 1971; Wessel and Watts, 1988). The statistical cross-over analysis shows than $84 \%$ of the values have differences below $10 \mathrm{mGal}$ and $64 \%$ of the cross-over errors are under $5 \mathrm{mGal}$ (Figure 5).

The levelling correction method used was a statistical levelling that corrects errors by modelling a trend surface to the intersection errors and removing the trend from the tie line data. To level the tie lines we assumed that the difference between the tie line and all crossing survey lines can be used as an estimate of the error along the tie line. It is reasonable to assume that the tie line should, on average, match the crossing lines. Any single line may be out of level, but the average of all lines should follow the correct tie line. The statistical levelling was first applied to individual cruises and later to all the cruises together because there are some lines that cross groups of lines of other cruises.

\section{Coherence analysis}

Because interpolation of the anomaly maps included both ship gravity data and satellite gravity data (ERS1, Geosat and Topex-Poseidon, from Sandwell and Smith, 1997) (Figure $6 \mathrm{a}, \mathrm{b}$ ), a spectral analysis of the coherence between both kind of data was done. The objective of this analysis was to check the precision and the existence of a cut-off frequency that marked a lower limit in the satellite data accuracy. The longest ship track (495 km length), with an E-W direction, was selected for the analysis (Line 001, Figure 3). In that line, the auto- and cross-spectrum were calculated for free air anomaly values obtained by both ship and satellite (Figures 6a,b). Because the sample interval was different in each case, about $50 \mathrm{~m}$ for the ship and $3500 \mathrm{~m}$ for the satellite, the larger sample interval was chosen for the analysis. To avoid aliasing, the ship data were low-pass filtered before re-sampling to the coarser interval. For that interval, we have calculated the spectral density by Welch's method (1967) of ensemble averaging of multiple overlapped windows, using the standard error estimates of Bendat and Piersol (1986) and following the Wessel and Smith (1995) procedure. Finally, we have plotted the spectra for the two sources and the coherence between them. Power values are equivalent in both types of data (Figure 6c). The coherence has values near 1 for long wave-lengths $>20 \mathrm{~km}$ (Figure 6d), while for 

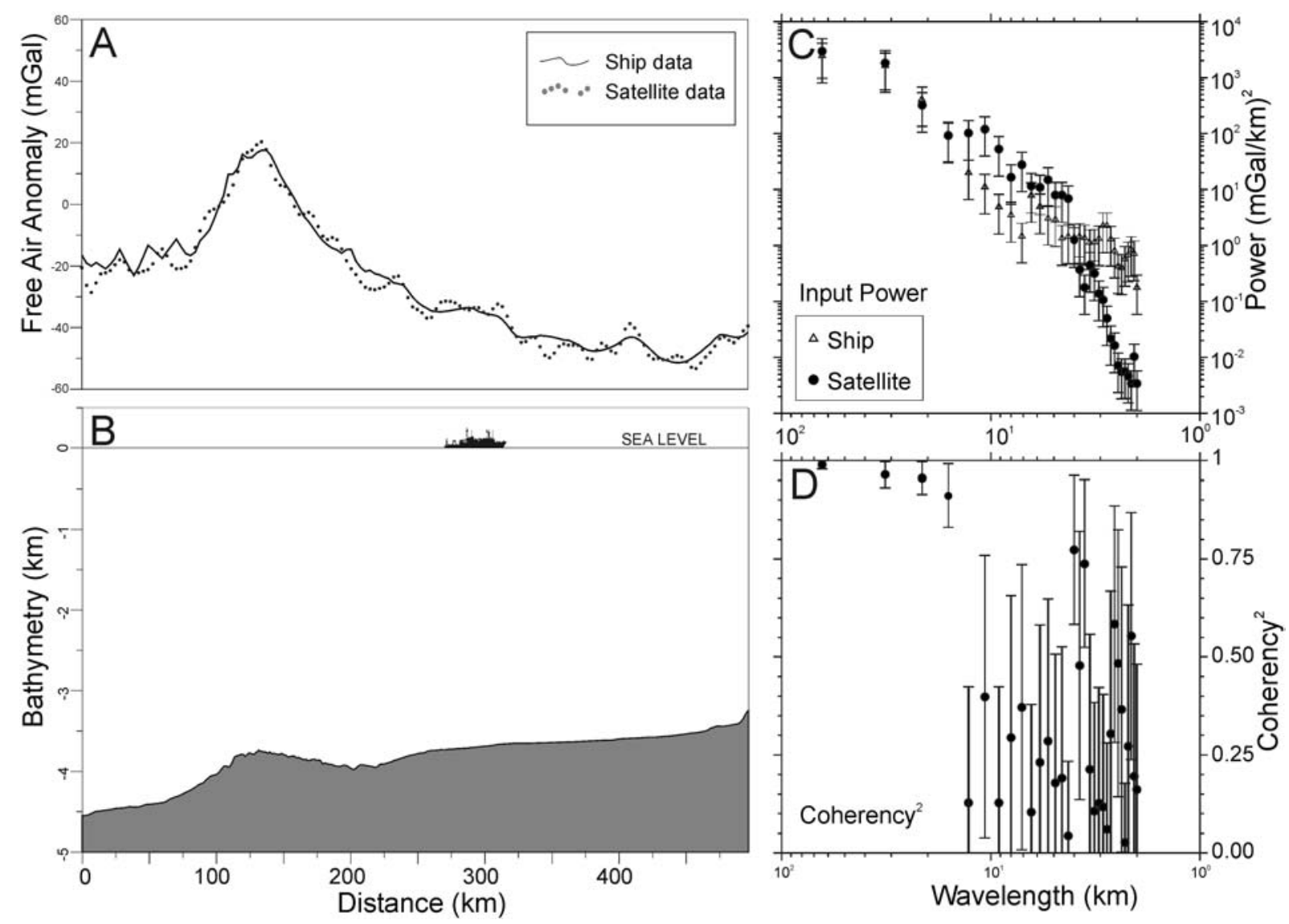

Figure 6. Coherence analysis of free air anomaly values. a) Representation of ship and satellite free air anomaly data for Line 001, sampling interval $3500 \mathrm{~m}$. b) Ship bathymetry profile for Line 001 (located in Figure 2), sampling interval $50 \mathrm{~m}$. c) Comparison of power spectrum of ship and satellite data along the line. d) Coherence analysis between ship and satellite gravity data along the line.

wavelengths shorter than $15 \mathrm{~km}$, there is low coherence between both data sets, as also suggested by the power values (Figures $6 \mathrm{c}, \mathrm{d}$ ). These data agree with the resolution of satellite data established at $22-30 \mathrm{~km}$ in previous works (Yale et al., 1995). The good results of the coherence analysis may be due to the systematic character and quality of the gravity data used. The spectrum also shows that satellite data are sparse between 6 and $12 \mathrm{~km}$ wavelength. Below this value only the ship data have a significant signal level. Because of the regional character of the research area, it is possible to use both kinds of data to get a synthesized map, knowing that, for satellite data only wavelengths above $15 \mathrm{~km}$ are reliable. On the other hand, results of the spectral analysis of the coherence indicate that for high resolution studies the use of ship gravity data is essential.

\section{Gravity maps}

\section{Map construction}

All filtered offshore gravity data were merged with gravity data onshore to construct free air and Bouguer anomaly maps. The combined data were interpolated using a Kriging algorithm that divides the search area into six sectors. After trying different grid cell sizes and taking into account the results of the spectral analysis, a $6 \mathrm{~km}$ grid cell size was chosen as the most suitable for this study. The final maps include the anomaly contours over an illuminated coloured image computed from a directional derivative in the $310^{\circ}$ direction and were drawn using GMT software (Wessel and Smith, 1995). The free air anomaly map was contoured at $10 \mathrm{mGal}$, while the Bouguer anomaly 

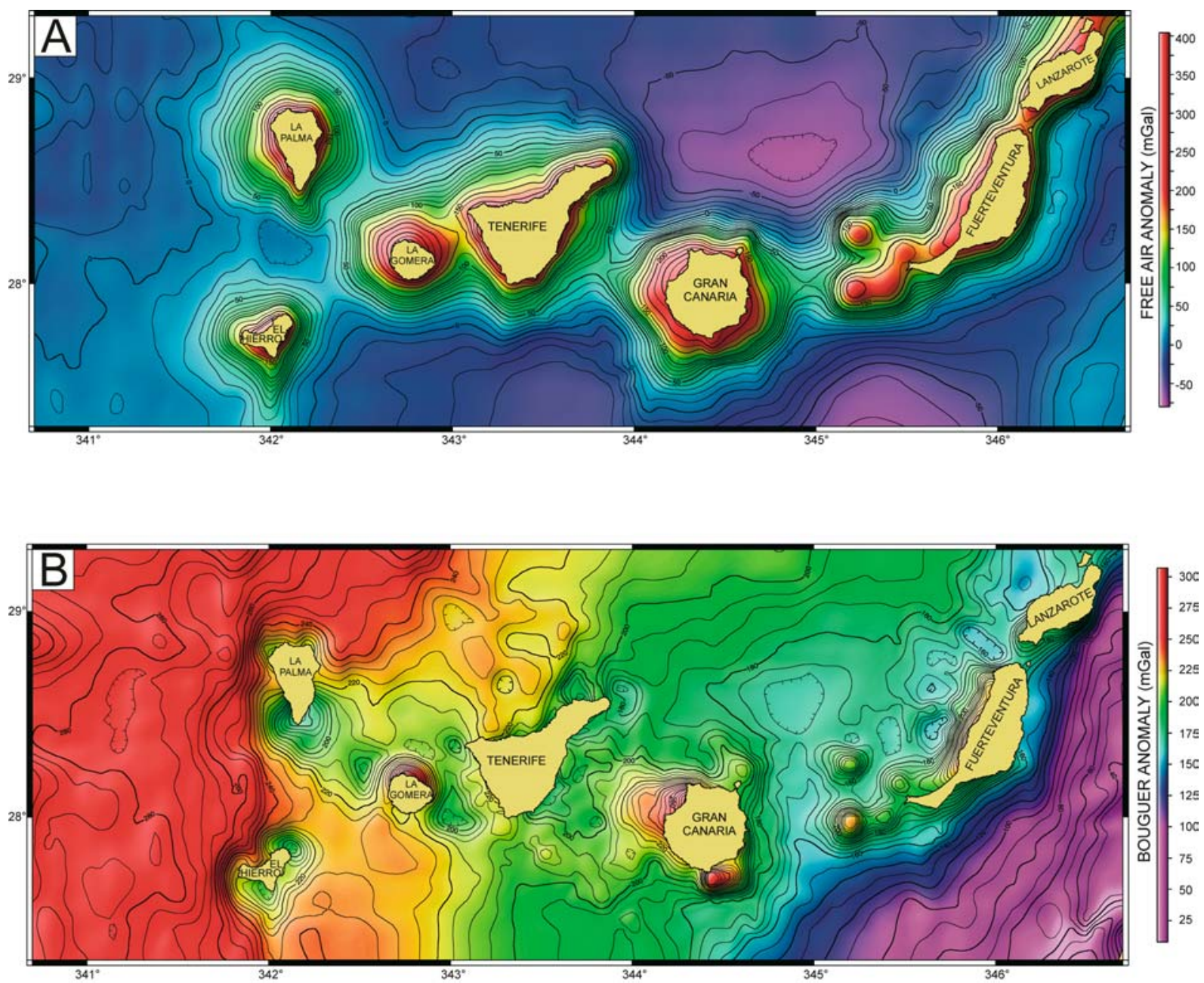

Figure 7. (a) Free air anomaly map (contour interval $=10 \mathrm{mGal}$ ). (b) Bouguer anomaly map (contour interval $=5 \mathrm{mGal}$, except to the east of Fuerteventura and Lanzarote where the contour interval $=10 \mathrm{mGal}$ ). The colour palette range has been emphasized for anomalies between $125-225 \mathrm{mGal}$.

map was contoured at $5 \mathrm{mGal}$, except in the area east of Fuerteventura and Lanzarote, where steep gravity gradients occur and a $10 \mathrm{mGal}$ contour was chosen (Figures 7a and 7b).

\section{Free air anomaly map}

The free air anomaly map is shown in Figure 7a. Values above $100 \mathrm{mGal}$ occur above sea level, reaching as much as $+400 \mathrm{mGal}$ on the highest island. Values between +100 and +50 mGal mark the submarine flanks of the islands with steep slopes. The $0 \mathrm{mGal}$ represents deep seafloor with less island influence. Minimum values of $-75 \mathrm{mGal}$ appear east of Tenerife, NE of Gran Canaria and west of Fuerteventura. Looking at the gradual distribution, from positive values on the island to negative values in deep areas, there is a clear correlation with bathymetry. This is expected, since free air anomalies are dominated by the large density contrast at the seafloor (Lin et al., 1990). As free air anomaly values have a dependence on the topography and bathymetry, it is not possible to derive a correct interpretation, even qualitatively, without taking account of bathymetry. For geological interpretations Bouguer anomaly values are more useful, especially when a sea bottom terrain correction is done, because the anomalies can be interpreted in terms of density variations below the water slab and depth of the sources that generate these variations. This allows us to make an detailed description and to be able to discuss the gravity data based on the Bouguer anomaly map. 
Bouguer anomaly map

The Bouguer anomaly map with both sea-bottom terrain and topography corrections is shown in Figure $7 \mathrm{~b}$. The Bouguer gravity values range from $+315 \mathrm{mGal}$ in the westernmost side to $+30 \mathrm{mGal}$ in the easternmost one. This change takes place in a steep and discontinuous way, shaped by three major elongated high gradient zones: near the eastern coast of Fuerteventura and Lanzarote, across Tenerife island (both with a NESW orientation) and just to the west of La Palma and El Hierro islands, with a N-S orientation. These high gradient zones separate four areas with different gravity responses. It is clearly observed that the Canary Islands occupy the two zones of intermediate Bouguer anomaly values (160-240 mGal). The mean value of the western islands is higher $(220 \mathrm{mGal})$ than the eastern ones $(180 \mathrm{mGal})$. In addition to the high gradient zones, there are other effects that disturb the general progressive variation in the Bouguer anomaly values from east to west, such as the presence of more local highs and lows and high gradient zones (Figures $7 \mathrm{~b}$ and 8).

There are some gravity highs of special relevance because of their signal amplitude: Two of them are related to Gran Canaria and another is centred on La Gomera. Other gravity highs, located SW of Fuerteventura, have shorter wavelengths but considerable amplitude (40-50 mGal).

There are some gravity lows west of Lanzarote and Fuerteventura, and it is remarkable that the axis of minimum values has a N-S direction in the channel between Fuerteventura and Gran Canaria. The biggest gravity lows, because of their amplitude values, are related to La Palma and El Hierro.

The map shows different kinds of signals, due to the small grid side and the large size of the studied area. This characteristic makes it necessary to apply frequency separation techniques to analyse the different anomalies and to avoid possible distortion due to their superposition.

\section{Gravity data filtering and transformation}

The Bouguer anomaly map shows a combination of long- and short-wavelength features. In order to better determine gravity gradients that may indicate geological contacts between bodies of different density, and to distinguish between deeper and shallower sources, we have applied the following filtering and transformation techniques: A) vertical derivative maps, by taking the 2-D Forward Fast Fourier Transform; and B) filtering of the Bouguer anomaly map in different wavelengths by applying Fourier analysis (cut-off wavelength values have been obtained by the 2-D spectral analysis of the Bouguer anomaly map described later in the text).

\section{First vertical derivative map}

The first vertical derivative enhances shorter wavelengths, suppresses longer wavelengths and is accomplished by multiplying the Fourier transform of a potential field map by the wavenumber. The effect is to enhance anomalies caused by abrupt lateral changes in near-surface densities at the expense of broader anomalies caused by deeper or more gradual density changes. For this reason, the map is useful for comparison of anomalies associated with geological bodies exposed at the surface. Suppression of longer wavelengths also helps in comparing and distinguishing trends and anomaly fabrics in various domains (Simpson et al., 1986; Jachens et al., 1989). As the first vertical derivative map (Figure 9) has considerable similarities with the short wavelength Bouguer anomaly map, we will discuss both maps together below.

\section{Bouguer anomaly filtered maps}

The Fourier analysis was done with the regularlyspaced Bouguer anomaly grid shown in Figure $7 \mathrm{~b}$. Figure 10 represents the radial-averaged power spectrum of the Bouguer anomaly grid. It consists of a number of linear trends, which can be interpreted in terms of the mean depth to the major density contrasts within the lithosphere following the method of Karner and Watts (1983). We recognize two linear segments of differentiated slope. The steeper one is related to deep sources (mean depth $=65 \mathrm{~km}$ ), responsible of long wavelength anomalies (between 200 and $40 \mathrm{~km}$ ), while the other represents the shallower sources (mean depth $=20 \mathrm{~km})$, responsible for short wavelength anomalies (between 40 and $12 \mathrm{~km}$ ).

Using the spectral analysis results we have obtained two maps of filtered Bouguer anomalies, one of long wavelengths that show deep density variations and/or crustal flexures, and another of short wavelengths, from which the noise has been eliminated, that represents local density variations of crustal scale. 


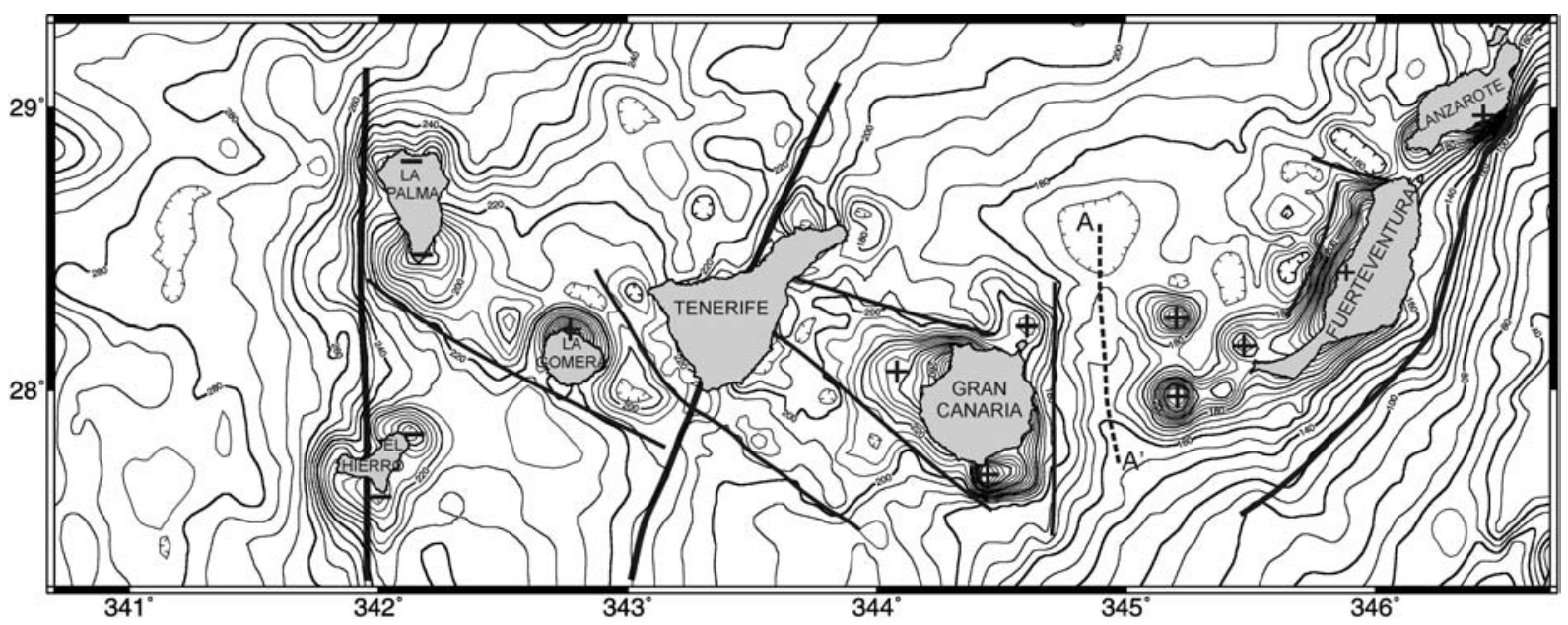

Figure 8. Interpreted Bouguer anomaly map (contour interval $=5 \mathrm{mGal}$, except to the east of Fuerteventura and Lanzarote where the contour interval $=10 \mathrm{mGal}$ ). Black solid lines show linear high gravity gradients. Gravity highs are represented with + symbols and gravity lows with - symbols. Dashed black line labelled as A-A' represent an axis of gravity lows. See text for explanation.

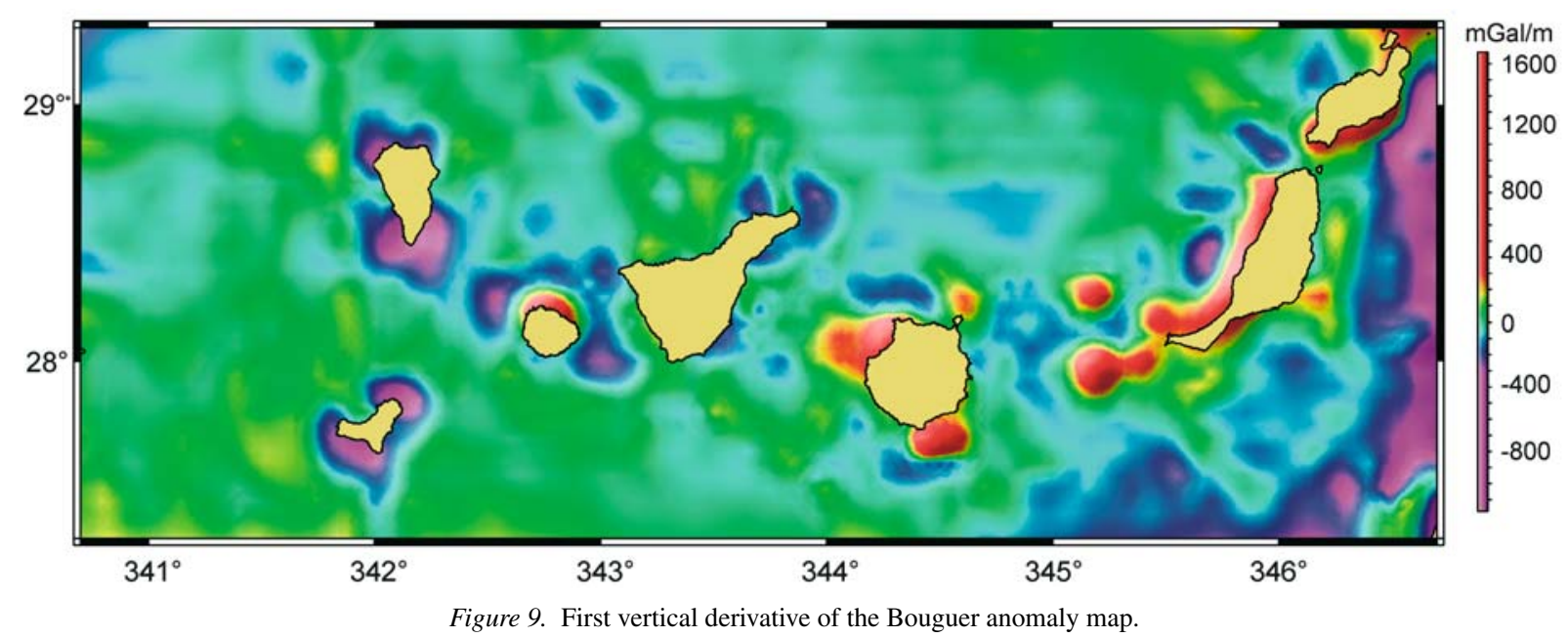

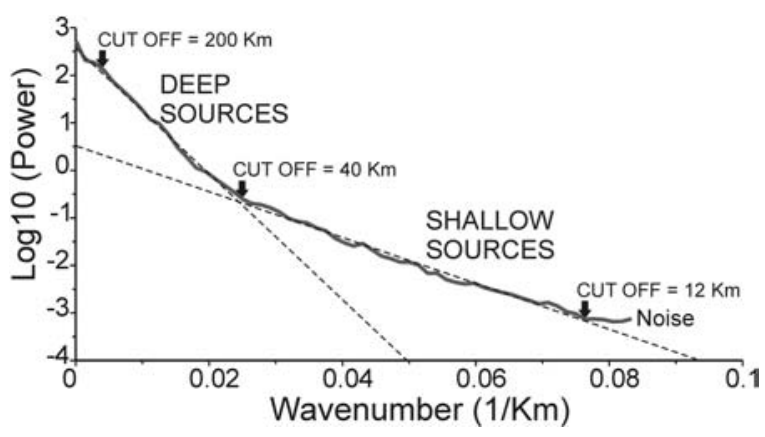

Figure 10. Radial-averaged power spectrum of Bouguer anomaly map and depth estimation for the density interfaces contributing to the long and short wavelengths.

\section{Long wavelength Bouguer anomaly map}

The description of the long wavelength Bouguer anomalies refers to the map of Figure 11a. It has some similarities with the Bouguer anomaly map (Figure $7 \mathrm{~b}$ ). As was mentioned previously, the change from low Bouguer anomalies in the east to high Bouguer anomalies in the west takes place in a steep and discontinuous way, allowing us to define four sectors separated by three major high gradient zones: - Lanzarote - Fuerteventura Gradient Zone (LFGZ). The easternmost gradient zone is located to the east of Lanzarote and Fuerteventura. It runs in a general NESW direction, although near Fuerteventura it takes a NNE-SSW direction. The maximum gradient values are reached near Lanzarote $(12 \mathrm{mGal} / \mathrm{km})$. 
- Tenerife Gradient Zone (TGZ). Crossing Tenerife in a NE-SW direction, there is a stronger gradient on the north side of the island than on the southern edge.

- La Palma - El Hierro Gradient Zone (PHGZ). This is the westernmost gradient trending $\mathrm{N}-\mathrm{S}$, and it passes west of La Palma and through El Hierro. In areas where it is not modified by wavelengths related to other anomalies, it reaches a $3.5 \mathrm{mGal} / \mathrm{km}$.

Some differentiated anomalies seen in the general map appear to have an overlap effect as a unique long wavelength anomaly, while there are others whose effects seem to be absent.

The two independent gravity highs of Lanzarote and Fuerteventura that are seen in the unfiltered general map (Figure 7b) have a reflection as a unique and elongated gravity high (Figure 11a). This trends parallel to Fuerteventura's west coast in the long wavelength map (H1) and includes the Amanay and El Banquete gravity highs. The various individual gravity highs observed in the general map in relation to Gran Canaria have a unique reflection (H2). The long wavelength of this high suggests a deep source.

The gravity lows west of Lanzarote and Fuerteventura that appear in the general Bouguer map (Figure $7 b$ ) have a possible reflection as a single gravity low anomaly of low amplitude and a NE-SW orientation (L1), with its position displaced towards the northwest (Figure 11a).

The gravity lows located south of La Palma and east of El Hierro are clearly visible in the long wavelength map (L2 and L3, Figure 11a) as isolated gravity lows displaced eastwards respect to their position in the general map (Figure 7b).

\section{Short wavelength Bouguer anomaly map}

The description of the short wavelength Bouguer anomalies refers to the map of Figure 11b. In this map, as well as in the vertical derivative one (Figure 9), gravity anomalies caused by shallow bodies and high gradient zones are clearly visible. A detailed description of the most significant gradient zones, gravity highs and gravity lows is given here:

- Gradient Zone G1. This zone is an E-W trending gradient, located between Lanzarote and Fuerteventura. It clearly separates the gravity highs located off both islands. The associated gradient, of at least $50 \mathrm{mGal}$, seems to separate and displace both gravity highs in a dextral sense.

- Gradient Zone G2. This zone is located west of Fuerteventura, separating the high values of
Fuerteventura's west flank of some gravity lows located to the west with a NE-SW direction. A change of $70 \mathrm{mGal}$ is observed over a distance of less than $15 \mathrm{~km}$.

- Gradient Zone G3. On the eastern flank of Gran Canaria there is a high gradient zone with N-S direction and a minimum Bouguer anomaly variation of 50 mGal.

- Gradient Zone G4. Zone G4 is located east of Tenerife and has an ENE-WSW orientation. Based on morphological criteria, a fault has been interpreted as occurring in the same place and having the same direction (Llanes et al., this issue). The fact that a density contrast is observed across the fault supports this interpretation.

- Gradient Zones G5, G6 and G7. There are three gradients with a NW-SE direction located between Tenerife and Gran Canaria. G4 and G5 are limited on the north and south, respectively, by a gravity high extending from Gran Canaria to Tenerife. Running between Tenerife and La Gomera there is a NW-SE axis of maximum values with a large longitudinal manifestation whose southern limit is the G7 gradient zone.

- Gradient Zone G8 is located south of La Palma and La Gomera with a NW-SE orientation. It separates a gravity high area to the south from an area of various gravity lows to the north with a change of $20 \mathrm{mGal}$ in $10 \mathrm{~km}$. In the northern area of gravity lows there is an isolated gravity high associated with La Gomera.

- Gravity highs H9 and H10. To the SE of Lanzarote there is a gravity high (H9) that has no continuation either towards the north or towards Fuerteventura. In contrast to the high located to the east, Fuerteventura has a gravity high on the west coast and its submarine flank (H10). Both highs are separated by the high gradient zone G1 described above.

- Gravity highs H3, H4 and H5. SW of Fuerteventura we find three closed gravity highs. $\mathrm{H} 3$ is located in the submarine flank of the Jandía Peninsula and the other two gravity highs (H4 and H5) are associated with the 'Amanay' and 'El Banquete' seamounts, respectively. - Gravity highs H6, H7 and H8. There are three gravity highs associated with Gran Canaria. The larger one, at the NW of the island (H6), is limited by gradients G4 and G5, and shows attenuation towards Tenerife. Another gravity high is located at the submarine continuation of 'La Isleta' peninsula (H7) and extends in a NW-SE direction. The third one appears at the south of the island (H8) with a strong gradient that reaches $75 \mathrm{mGal}$ in just $10 \mathrm{~km}$. 

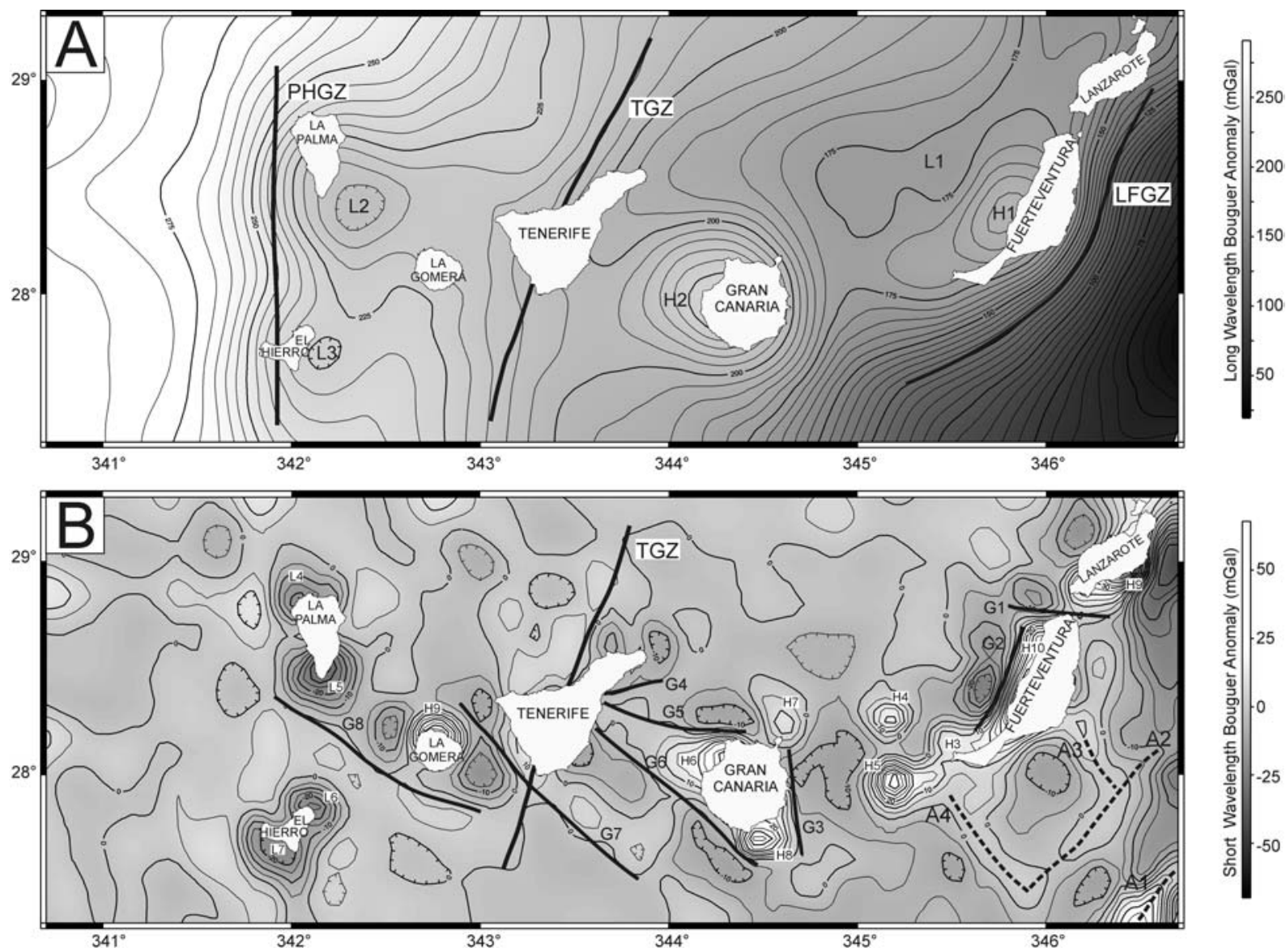

Figure 11. Low- and high-pass filtered maps. Black solid lines show linear high gravity gradients (LFGZ, TGZ and PHGZ). Gravity highs are marked as $\mathrm{H}$ and gravity lows as L. a) Long wavelength anomaly map $(\lambda>40 \mathrm{~km})$. b) Short wavelength anomaly map $(12 \mathrm{~km}<\lambda<40 \mathrm{~km})$. Dashed black lines (labelled as A1 to A4) represents axes of gravity highs. See text for explanation.

- Gravity high H9. La Gomera has a very well defined gravity high that is located at the north side of the island.

- Gravity lows L4 and L5. Located near La Palma, there are two remarkable gravity lows, one in the north and the other in the southern region. The southern one exhibits a larger geographic extent and amplitude than the northern one.

- Gravity lows L6 and L7. Two gravity lows, close to each other, are associated with El Hierro, one towards the NE and the other towards the SW.

Other features that were not observed in the Bouguer anomaly unfiltered map appear clearly after filtering. For example in the SE area of the map, nearest to the African continent, a net aspect is seen with two principal orthogonal directions, NE-SW (A1 and A2) and NW-SE (A3 and A4).

\section{Geodynamic discussion of the gravity data}

The new gravity data available and its qualitative and quantitative interpretation, together with other geologic and geophysical data, allow us to discuss different aspects of geodynamic interest. The main features observed in the Bouguer anomaly maps are fundamentally linked to three characteristics:

- The change shown in the Bouguer anomaly values, which oscillate between $30 \mathrm{mGals}$ in the eastern edge to $320 \mathrm{mGal}$ in the occidental one.

- The discontinuous way this change takes place, clearly conditioned by the three high gradient zones previously described: LFGZ, TGZ and PHGZ (Figures 8 and 11a).

- The general orientation of the Bouguer anomaly contours. There is a NE-SW trend in the eastern area 
(nearest to the Africa continent) which progressively changes to a N-S direction towards the western edge, as we advance to more 'oceanic' areas.

Anomaly values under $40 \mathrm{mGals}$ located in the SE edge of the research area seem to indicate the presence of continental crust. Between the values of $40 \mathrm{mGals}$ and east of Fuerteventura and Lanzarote, where values of $140 \mathrm{mGal}$ are found, the crust has a transitional character. In this area, with values around $140 \mathrm{mGal}$ to the west, change takes place abruptly at the LFGZ.

All of the study area located west of LFGZ has Bouguer anomaly values between 140 and $320 \mathrm{mGal}$, which typically correspond to oceanic crust (e.g. Talwani et al., 1965). The evolution of the anomalies in this area is not defined in a continuous way. There are areas of small increments, limited by narrow high gradient zones (TGZ and PHGZ).

The Canary Islands are located between two high gradient zones, LFGZ and PHGZ (140-250 mGal) and there is a high gradient zone (TGZ) that divides the archipelago into two areas. The eastern islands (Lanzarote, Fuerteventura, Gran Canaria and part of Tenerife) are located in an area of lower Bouguer anomaly values than the western islands (La Gomera, La Palma, El Hierro, and probably part of Tenerife). From the PHGZ towards the west, high Bouguer anomaly values are higher than $250 \mathrm{mGal}$, and could correspond to normal oceanic lithosphere not affected by hotspot volcanism.

The closer to the continent, the more pronounced the NE-SW orientation of the gravity anomaly contours becomes, hile in the west, they become more $\mathrm{N}-\mathrm{S}$ oriented. In this sense, the variation in the high gradient zones orientation confirms an increase of the oceanic influence towards the west, because they are more parallel to the fabric of the oceanic crust.

In the island area, between LFGZ and PHGZ, there are some closed anomalies, several tens of $\mathrm{km}$ in diameter. Important differences have been observed between them. In the western islands the anomalies are gravity lows (L1 and L2, Figure 11a), while in the eastern islands they are gravity highs $(\mathrm{H} 1$ and $\mathrm{H} 2$, Figure 11a). In the central islands (Tenerife and La Gomera) these types of anomalies are absent. The displaced position of the gravity lows of the western islands with respect to the centre of the islands and its high wavelengths suggest the influence of the upper mantle as a source for these anomalies. The gravity highs observed in the eastern islands are eccentric for Fuerteventura and centred on Gran Canaria. In the first case the sources can be related to crustal density changes, flexures in the crust (as it is located near the transitional area) and upper mantle related effects. For Gran Canaria the source of the anomaly can be associated with crustal density variations and mantle related effects. The absence of this kind of anomaly in relation with Tenerife and La Gomera is of special interest.

Smaller gravity anomalies and high gradient zones overlie the main features, indicating the presence of more localized structures near the surface. Some of these gradients have a rectilinear layout which together with other geophysical and geological information, allow us to interpret them as fracture zones: a) The E-W gravimetric gradient (G1, Figure 11b) that separates and displaces in a dextral sense the gravity highs of Lanzarote and Fuerteventura. On both sides of this gradient the crust has different thickness and seismic velocity characteristics (Dañobeitia and Canales, 2000); b) Another gravity gradient is the $\mathrm{N}-\mathrm{S}$ oriented structure located east of Gran Canaria (G3, Figure 11b) which limits an axis of minima with a $\mathrm{N}-\mathrm{S}$ orientation (Figure 8). In this area there is a strong structural control to the orientation of submarine canyons that sharply changes its direction to N-S, as can be seen in bathymetric maps (Llanes, 2000; Acosta et al., this issue); c) The channel between Tenerife and Gran Canaria is structured by gravimetric gradients of NW-SE direction (G5, G6 and G7, Figure 11b) and a strong structural control in this direction can be also inferred from the morphology when looking at detailed bathymetry (Acosta et al., this issue). An important NE-SW fracture has been traditionally interpreted in this channel (Dash and Bosshard, 1969; Bosshard and MacFarlane, 1970; Mezcúa et al., 1992), but there is no gravimetric evidence related to it. This is the area with the highest seismic activity within the instrumented period. An earthquake of 5.2 magnitude (09/05/1989) was provisionally interpreted as being related to a strike-slip fault of possible NE-SW direction (Mezcúa et al., 1992). However, there is another solution calculated for the same earthquake (CMT Catalogue, Dziewoinski et al., 1981) as a reverse strike-slip focal mechanism that implies the possible presence of an E-W or a NW-SE fault. There are gravimetric gradients with both directions in the channel, but none with a NE-SW orientation; d) The last gravimetric gradient interpreted as a fault is located between Tenerife and La Gomera with a NW-SE direction (G7). The detailed bathymetry also shows a strong structural control with the same direction (Acosta et al., this issue). In this location, Dash and Bosshard (1969) and Bosshard and MacFarlane 
(1970) interpreted a fault running from El Hierro to La Gomera and Tenerife, perpendicular to the one proposed here (G7). However, no gravity evidence to support this has been found on our Bouguer anomaly maps.

The gravity highs located in Fuerteventura and $\mathrm{La}$ Gomera (H2 and $\mathrm{H} 9)$ are interpreted here as being produced by the presence of the Basal Complex that outcrops on both islands. The Basal Complex (Bravo, 1952; Fúster et al., 1968, Ancoechea et al., 2003) is a thick Upper Cretaceous sedimentary sequence overlaid by submarine volcanoes and intruded by an intense NNE-SSW trending sheeted dyke swarm, which formed in association with the location of alkaline plutons. Their outcrops have been found on three islands: Fuerteventura, La Gomera and La Palma. On La Palma, the Basal Complex outcrops in the central area of the island, where a relative gravity high is observed, but it is partially masked by two gravity lows (L4 and L5, Figure 11b). When comparing the described gravity highs related to the Basal Complex with that on Gran Canaria, we found some similarities. Two of the described gravity highs related to it (H6 and $\mathrm{H} 8$ ) have very high relative values of Bouguer anomalies, which could suggest the possible presence of the Basal Complex near the surface (although there is no outcrop on the island). There are also some positive anomalies of short wavelength and high amplitude in the submarine extension of Fuerteventura (H3, H4 and H5) that we interpret as high density intrusive bodies.

\section{Conclusions}

From a methodology point of view it is necessary to study Bouguer anomaly maps and not only free air anomaly maps, in order to avoid water influence and to have enough resolution for marine geological interpretation. This is because Bouguer anomalies enhance sub-seafloor density changes.

From a geodynamic point of view it is remarkable that the Canary Islands have complex gravity characteristics. The explanation is the superposition of different effects. The following conclusions can be drawn on the basis of this study:

- Bouguer anomaly values above $140 \mathrm{mGal}$ have been observed for all the islands in the Canary Archipelago, which suggests an oceanic crustal character.

- Two areas are differentiated by their Bouguer anomaly values, one between 140 and $320 \mathrm{mGal}$ that corresponds to oceanic crust, and the other under $140 \mathrm{mGal}$ related with the transition and continental crust. The oceanic crust, located to the west, is separated from the transitional crust by the high gradient zone LFGZ. - The area of oceanic crust can be divided into three bands limited by two high gradient zones, TGZ and PHGZ.

- The orientation of the high gradient zones LFGZ, TGZ and PHGZ progressively varies from NE-SE, in the eastern edge, to N-S in the western edge. This variation reflects an increasing oceanic influence towards the east.

- Circular anomalies with various tens of $\mathrm{km}$ in diameter located in the eastern and western islands may have different origins. The gravity lows observed in western islands may be related to upper mantle effects, while the gravity highs observed in the eastern islands may be related to mantle and crustal effects. In the central islands (Tenerife and La Gomera) these kind of anomalies are absent.

- The gravity highs of Fuerteventura, La Gomera and La Palma are related with the Basal Complex. The gravity highs of Gran Canaria and the areas of 'Amanay Bank' and 'El Banquete Bank', located southwest of Fuerteventura, are produced by high density intrusive bodies.

- There are some high gravity gradients that present a linear layout and their study, together with other geophysical and geological information, allows us to interpret them as fracture areas. These fracture areas have not been correctly interpreted until now or were assigned to a different structural direction.

\section{Acknowledgements}

This work was funded by the EEZ project (Oceanographic and Hydrographic Research of the Spanish Economic Exclusive Zone) and the 'Universidad Complutense de Madrid'. We thank the 'Conserjería de Educación de la Comunidad de Madrid y Fondo Social Europeo' for pre-doctoral grants awarded to Pilar Llanes and Juan Álvarez. We also thank the captain, officers and crew of RV Hespérides on cruises EEZ-98, EEZ-99 and EEZ-2000 for their cooperation at sea. Finally, we are grateful for the efforts of reviewers whose comments have helped improved the manuscript.

\section{References}

Ablay, G.J. and Kearey, P., 2000. Gravity constraints on the structure and volcanic evolution of Tenerife, Canary Islands, J. Geophys. Res. 105 (B3): 5783-5796. 
Acosta, J., Palomo, C., Uchupi, E., Muñoz, A., Escartin, J., Herranz, P. and Sanz, J.L., 1997. Morphology and seismic character of north slope of Tenerife, Canary Island. Evidence for episodic massive landslides, J. Geophys. Res. 102: 20325-20342.

Acosta, J., Uchupi, E., Muñoz, A., Herranz, P., Palomo, C., Ballesteros, M. and EEZ Working Group, this issue. Geologic evolution of the Older Canary Islands: Lanzarote, Fuerteventura, Gran Canaria and La Gomera, with a Brief description of the avalanches on the Younger Islands: Tenerife, La Palma and El Hierro, Mar. Geophys. Res..

Ancochea, E., Fúster, J.M., Ibarrola, E., Cendrero, A., Coello, J., Hernan, F., Cantagrel, J.M. and Jamond, C., 1990. Volcanic evolution of the island of Tenerife (Canary Islands) in the light of new K-Ar data, J. Volcanol. Geotherm. Res. 44: 231-249.

Ancochea, E., Brändle, J.L., Huertas, M.J., Cubas, C.R. and Hernán, F., 2003. The felsic dikes of La Gomera (Canary Islands): identification of cone sheet and radial dike swarms, J. Volcanol. Geotherm. Res. 120: 197-206.

Anguita, F. and Hernán, F., 2000. The Canary Islands origin: a unifying model, J. Volcanol. Geotherm. Res. 103 (1-4): 1-26.

Araña, V., Camacho, A.G., García, A., Montesinos, F.G., Blanco, I., Vieira, R. and Felpeto, A., 2000. Internal structure of Tenerife (Canary Islands) based on gravity, aeromagnetic and volcanological data, J. Volcanol. Geotherm. Res. 103 (1-4): 4364.

Banda, E., Dañobeitia, J.J., Surinach, E. and Ansorge, J., 1981. Features of crustal structure under the Canary Islands, Earth Planet. Sci. Lett. 55: 11-24.

Bendat, J.S. and Piersol, A.G., 1986. Random data, 2nd revised ed., John Wiley and Sons.

Blakely, R.J., Potential theory in gravity and magnetic applications, Cambridge University Press, Cambridge, 1-441, 1995.

Bosshard, E. and MacFarlane, D.J., 1970. Crustal structure of the western Canary Islands from seismic refraction and gravity data, J. Geophys. Res. 75: 4901-4918.

Bravo, T., 1952. Aportación al estudio geomorfológico y geológico de la costa de la fosa tectónica del valle de la Orotava, Bol. $R$. Soc. Esp. Hist. Nat., Tomo L, 1-30.

Camacho, A.G., Montesinos, F.G., Vieira, R. and Arnoso, J., 2001. Modelling of crustal anomalies of Lanzarote (Canary Islands) in light of gravity data, Geophys. J. Int. 147: 403-414.

Canales, J.P. and Dañobeitia, J.J., 1998. The Canary Islands swell: a coherence analysis of bathymetry and gravity, Geophys. J. Int. 132: 479-488.

Carracedo, J.C., Day, S.J., Guillou, H., Rodriguez Badiola, E., Canas, J.A. and Pérez Torrado, F.J., 1998. Hotspot volcanism close to a passive continental margin: the Canary Islands, Geol. Mag. 135 (5): 591-604.

Dañobeitia, J.J., Canales, J.P. and Dehghani, G.A., 1994. An estimation of the elastic thickness of the lithosphere in the Canary Archipelago using admittance function, Geophys. Res. Lett. 21: 2649-2652.

Danés, Z.F., 1982. Short note: An analityc method for the determination of distant terrain corrections, Geophysics 47 (10): 1453-1455.

Dañobeitia, J.J. and Canales, J.P., 2000. Magmatic underplating in the Canary Archipelago, J. Volc. Geother. Res. 103: 27-41.

Dash, B.P. and Bosshard, E., 1969. Seismic and gravity investigations around the Western Canary Islands, Earth Planet. Sci. Lett. 7: $169-177$

Dziewoinski, A.M., Chou, T.A. and Woodhouse, J.H., 1981. Determination of earthquakes source parameters from waveform data for studies of global and regional seismicity, J. Geophys. Res. 86: 2825-2852.
Hausen H., 1962. New contributions to the geology of Gran Canary (Gran Canaria, Canary Islands), Soc. Sci. Finnica, Comment. Phys.-Math. 27 (1): 418.

I.G.N. (Instituto Geográfico Nacional de España), 1996. Banco de datos gravimétricos de España. Ministerio de Fomento. Internal Repport.

Jachens, R.C., Simpson, R.W. and Blakely, R.J., 1989. Isostatic residual gravity and crustal geology of the United States, Geol. Soc. Am. Bull. 172: 405-423.

Jin, Y., McNutt, M.K. and Zhu, Y., 1994. Evidence from gravity and topography data for folding of Tibet, Nature 371: 669-674.

Karner, G.D. and Watts, A.B., 1983. Gravity anomalies and flexure of the lithosphere at Mountain Ranges, J. Geophys. Res. 88 (B12), 10449-10477.

Lin, J., Purdy, G.M., Schouten, H., Sempere, J.C. and Zervas, C., 1990. Evidence from gravity data for focused magmatic accretion along the Mid-Atlantic Ridge, Nature 344: 627632.

Llanes, P., 2000. Análisis morfoestructural basado en técnicas geofísicas del margen submarino centro-oriental del archipiélago Canario, Bachelor Thesis, Universidad Complutense de Madrid, $133 \mathrm{p}$.

MacFarlane, D.J. and Ridley, W.I., 1968. An interpretation of gravity data for Tenerife, Canary Islands, Earth Planet. Sci. Lett. 4: 481-486.

MacFarlane, D.J. and Ridley, W.I., 1969. An interpretation of gravity data for Lanzarote, Canary Islands, Earth Planet. Sci. Lett. 6: 431-436.

Mezcua, J., Buforn, E., Udías, A. and Rueda, J., 1992. Short note: Seismotectonics of the Canary Islands, Tectonophysics 208: 447452.

Nettleton, L.L., 1976. Gravity and magnetics in oil exploration. New York, Mac Graw-Hill.

Plouff, D., 1976. Gravity and magnetic fields of polygonal prisms and application to magnetic terrain corrections, Geophysics 41: 727-741.

Ranero, C.R., Torné, M. and Banda, E., 1995. Gravity and multichannel seismic reflection constraints on the lithospheric structure of the Canary swell, Mar. Geophys. Res. 17, 519-534.

Russo, R.M. and Speed, R.C., 1994. Spectral analysis of gravity anomalies and the architecture of tectonic wedging, NE Venezuela and Trinidad, Tectonics 13 (3): 613-622.

Roest, W.R., Dañobeitia, J.J., Verhoef, J. and Collete, B.J., 1992. Magnetic anomalies in the Canary Basin and the Mesozoic evolution of the Central North Atlantic, Mar. Geophys. Res. 14: $1-24$.

Rothe, P. and Schmincke, H.V., 1968. Contrasting origins of the eastern and western islands of the Canarian Archipelago, Nature 218: 1152 .

Sandwell, D.T. and Smith, W.H.F., 1997. Marine gravity anomaly form Geosat and ERS 1 satellite altimetry, J. Geophys. Res. 102 (B-5), 10039-10054.

Smith, W.H.F. and Sandwell, D.T., 1997. Global seafloor topography from satellite altimetry and ship depth soundings, Science 277: 1957-1962.

Simpson R.W., Jachens, R.C. and Blakely, R.J., 1986. A new isostatic residual gravity map of the Conterminous United States with a discussion on the significance of isostatic residual anomalies, J. Geophys. Res. 91 (B-8), 8348-8372.

Stillman, C.J., Fuster, J.M., Bennell-Baker, M.J., Muñoz, M., Smewing, J.D. and Sagredo, J., 1975. Basal complex of Fuerteventura (Canary Islands) is an oceanic intrusive complex with rift-system affinities, Nature 257: 469-470. 
Talwani, M., Le Pichon, X. and Ewing, M., 1965. Crustal structure of the mid-ocean ridges 2 . Computed from gravity and seismic refraction data, J. Geophys. Res. 70: 341-352.

Talwani, M., 1971. Gravity in the Sea, 4 (1), edited by A. Maxwell, 251-297, John Wiley, New York.

Vieira, R., Toro, C. and Araña, V., 1986. Microgravimetric survey in the Caldera of Teide, Tenerife, Canary Islands, Tectonophysics 130: $249-257$.

Watts, A.B., 1994. Crustal structure, gravity anomalies and flexure of the lithosphere in the vicinity of the Canary Islands, Geophys. J. Int. 119: 648-666.

Watts, A.B. and Talwani, M., 1975. Gravity Field of the Northwest Pacific Ocean Basin and its Margin: Hawaii and Vicinity, The Geological Society of America, Inc., Map and Chart Series MC9.

Watts, A.B. and Marr, C., 1995. Gravity anomalies and the thermal and mechanical structure of rifted continental margins, in Rifted Ocean-Continent Boundaries, NATO Science Series II: Mathematics, Physics and Chemistry, 463, edited by E. Banda et al., Kluwer Academic Publishers, Dordrecht, 65-94.
Watts, A.B., Pierce, C., Collier, J., Dalwood, R., Canales, J.P. and Henstock, T.J., 1997. A seismic study of lithosphere flexure in the vicinity of Tenerife, Canary Islands. Earth Planet. Sci. Lett. 146: 431-447.

Welch, P.D., 1967. The use of Fast Fourier Transform for the estimation of power spectra: a method based on time averaging over short, modified peridograms, IEEE Transactions on Audio and Electroacoustics, vol. AU-15, 2.

Wessel, P. and Watts, A.B., 1988. On the Accuracy of Marine Gravity Measurements, J. Geophys. Res. 93 (B-1): 393-413.

Wessel P. and Smith, W.H.F., 1995. New Version of the Generic Mapping Tools (GMT), http:/www.agu.org/eos_els, American Geophysical Union.

Yale, M.M., Sandwell, D.T. and Smith, W.H.F., 1995. Comparison of along-track resolution of stacked Geosat, ERS 1, and TOPEX satellite altimeters, J. Geophys. Res. 100 (B-8), 15117-15127.

Ye, S., Canales, J.P., Rihm, R., Dañobeitia, J.J. and Gallart, J., 1999. A crustal transect through the northern and northeastern part of the volcanic edifice of Gran Canaria, Canary Islands, J. Geodyn. 28: $3-26$. 